\title{
Impact of unhealthy lifestyle on cardiorespiratory fitness and heart rate recovery of medical science students
}

\author{
Lampson M. Fan ${ }^{1,2}$, Adam Collins², Li Geng ${ }^{2,3}$ and Jian-Mei Li ${ }^{2,3^{*}}$
}

\begin{abstract}
Background: Medical science students represent valuable labour resources for better future medicine and medical technology. However, little attention was given to the health and well-being of these early career medical science professionals. The aim of this study is to investigate the impact of lifestyle components on cardiorespiratory fitness and heart rate recovery measured after moderate exercise in this population.

Methods: Volunteers without documented medical condition were recruited randomly and continuously from the first-year medical science students during 2011-2014 at the University of Surrey, UK. Demographics and lifestyle components (the levels of smoking, alcohol intake, exercise, weekend outdoor activity and screen-time, daily sleep period, and self-assessment of fitness) were gathered through pre-exercise questionnaire. Cardiorespiratory fitness $\left(\mathrm{VO}_{2} \mathrm{max}\right)$ and heart rate recovery were determined using Åstrand-Rhyming submaximal cycle ergometry test. Data were analysed using SPSS version 25.

Results: Among 614 volunteers, 124 had completed both lifestyle questionnaire and the fitness test and were included for this study. Within 124 participants (20.6 \pm 4 years), $46.8 \%$ were male and $53.2 \%$ were female, $11.3 \%$ were overweight and $8.9 \%$ were underweight, $8.9 \%$ were current smokers and $33.1 \%$ consumed alcohol beyond the UK recommendation. There were $34.7 \%$ of participants admitted to have $<3 \mathrm{~h} /$ week of moderate physical activity assessed according to UK Government National Physical Activity Guidelines and physically not fit (feeling tiredness). Fitness test showed that $\mathrm{VO}_{2}$ max distribution was inversely associated with heart rate recovery at 3 min and both values were significantly correlated with the levels of exercise, self-assessed fitness and BMI. Participants who had $<3 \mathrm{~h}$ /week exercise, or felt not fit or were overweight had significantly lower $\mathrm{VO}_{2}$ max and heart rate recovery than their peers.
\end{abstract}

Conclusion: One in three new medical science students were physically inactive along with compromised cardiorespiratory fitness and heart rate recovery, which put them at risk of cardiometabolic diseases. Promoting healthy lifestyle at the beginning of career is crucial in keeping medical science professionals healthy.

Keywords: Physical activity, Cardiorespiratory fitness, Heart rate recovery, Lifestyle, Medical science students

\footnotetext{
* Correspondence: jian-mei.li@reading.ac.uk

${ }^{2}$ Faculty of Health and Medical Sciences, University of Surrey, Guildford, UK

${ }^{3}$ School of Biological Sciences, Harborne Building, University of Reading, Whiteknights, Reading RG6 6AS, UK

Full list of author information is available at the end of the article
}

C C The Author(s). 2020 Open Access This article is licensed under a Creative Commons Attribution 4.0 International License, which permits use, sharing, adaptation, distribution and reproduction in any medium or format, as long as you give appropriate credit to the original author(s) and the source, provide a link to the Creative Commons licence, and indicate if changes were made. The images or other third party material in this article are included in the article's Creative Commons licence, unless indicated otherwise in a credit line to the material. If material is not included in the article's Creative Commons licence and your intended use is not permitted by statutory regulation or exceeds the permitted use, you will need to obtain permission directly from the copyright holder. To view a copy of this licence, visit http://creativecommons.org/licenses/by/4.0/. The Creative Commons Public Domain Dedication waiver (http://creativecommons.org/publicdomain/zero/1.0/) applies to the data made available in this article, unless otherwise stated in a credit line to the data. 


\section{Background}

Recently, the number of university students in subjects affiliated to medicine or health care has risen markedly in particular for females [1]. People often assume that medical science education provides greater knowledge to students to keep them healthy and fit. In recent years, great effort has been given on the well-being and the quality of life to patients and other populations [2, 3] but few studies have assessed the well-being of young medical science professionals $[4,5]$. At the early stage of their careers, new medical science students are more vulnerable to adopt unhealth lifestyle, which may be due to the challenge of living independently without parental constraints, changing eating behaviour, high academic demands with longer sedentary period at lectures and computer-screen and managing an active social life in the meantime [4]. A recent survey reported that in comparison to pre-university life, new university students struggled to find time for exercise in order to keep them physically fit [4]. Understanding the impact of unhealthy lifestyle components on cardiorespiratory fitness (CRF) and heart rate recovery of new medical science students is an important step to keep this young generation healthy. However, few studies had examined the health of medical science students relied on self-reported data $[4,5]$. Little information is available based on objective physical activity measures and the association between these measures and the lifestyle components for these early career health professionals.

Physical activity, optimal body mass index (BMI), diet, and non-smoking are recommended lifestyle components for cardiovascular health $[2,6]$. Physical inactivity has been recognised as one of the leading causes of premature mortality [7] with an estimated health cost in UK around $£ 0.8$ billion per year [8]. Current UK government National Physical Activity Guidelines recommends at least $2.5 \mathrm{~h} /$ per week (or $30 \mathrm{~min} /$ day) of moderate intensity activity for adults (19-64 years old) [9]. Regular exercise during early adulthood provides vascular protection and lower disease burden in later life. On the other hand, poor fitness and low aerobic performance are often associated with a sedentary lifestyle, which is a well-described risk factor for the development of metabolic and cardiovascular disorders [10, 11].

Cardiorespiratory fitness (CRF) has been widely used to measure individual's aerobic exercise performance and is a predicative marker for cardiovascular health [11-13]. The maximal rate of $\mathrm{O}_{2}$ consumption $\left(\mathrm{VO}_{2} \mathrm{max}\right)$ is a measure of CRF [14-16] . Low $\mathrm{VO}_{2} \mathrm{max}$ is also an independent predictor of cardiovascular mortality and morbidity $[17,18]$. Heart rate recovery (HRR) after the cessation of physical exercise is another established prognostic indicator for cardiovascular events and all-cause mortality [19]. The objective of this study was to investigate the impact of modern lifestyles on cardiorespiratory fitness of young medical science students. To do this, we collected information of lifestyle components (levels of physical activity, BMI, smoking, alcohol use, daily sleep period and sedentariness) and examined their possible correlations with CRF and HRR measured individually in a cohort of 124 new medical science students. Information and findings from this study can be used for planning and developing a holistic approach to promote physical fitness of young adults at university and to improve their life expectancy after university.

\section{Methods}

\section{Study design and ethics}

This study was approved by the research ethics committee of the Faculty of Health and Medical Science at the University of Surrey, UK. Volunteers, both male and female, were recruited randomly and anonymously from the first-year medical science students who attended the human physiology practical classes during year 2011 to 2014 in the Faculty of Health and Medical Sciences, University of Surrey, UK. Prior to the study, volunteers were provided with the study information and consent documents. The inclusion criteria were first year undergraduate students between the ages of 18-35 without documented medical conditions. Exclusion criteria were above the age of 35 and evidence of medical conditions. Participants who failed to answer all questions in the survey form or failed to complete the fitness test or missing exercise data recording were excluded from the study. Data were collected anonymously and entered electronically for statistical analysis.

\section{Demographics and lifestyle information and cardiorespiratory fitness assessment}

Information pertaining to individual demographics and lifestyle components were collected through preexercise questionnaires specifically designed in whole for this study (Supplemental Additional file 1). Demographics included gender, age, ethnic origin, medical conditions and home country of residence. Lifestyle components included alcohol consumption (units/ week); current smoking status (cigarettes/week); levels and duration of physical activity (in terms of exercise and sport, h/week); sleep duration (h/day); weekend outdoor activity (h/day), and sedentary screen-time including computing, watching $\mathrm{TV}$ and gaming (h/ day), and self-perceptions of physical fitness. Current smokers are defined as individual who has smoked 100 cigarettes previously and currently smoke according to Centre for Disease Control and Prevention (CDC, USA) [20]. Body height and weight were measured and recorded by the investigators before the exercise test, and used to calculate BMI. Resting blood 
pressure (BP) and heart rate (HR) were taken prior to the fitness test. Åstrand-Rhyming submaximal cycle ergometry test was performed using the protocol as described previously [21,22]. It consisted of a $6 \mathrm{~min}$ exercise bout on a cycle ergometer (KORR Medical Technologies Int, USA). Power output of $75-125 \mathrm{~W}$ was used for female, and 100-150 W for male. Participants were instructed to maintain a pedal frequency of $50 \mathrm{rpm}$. Heart rate during exercise was recorded continuously using an infra-red ear lobe clip monitor. The criteria for exhaustion were heart rate at $\sim 185$ beats per minute and a subjective judgment by the investigators that the participant could no longer keep up. CRF was expressed as $\dot{\mathrm{V}}{ }_{2} \max \left(\mathrm{ml}^{1} \mathrm{~kg}^{-1} \cdot \mathrm{min}^{-1}\right)$ calculated using the Astrand and Ryhming nomogram [22]. The heart rate recovery and the $\mathrm{BP}$ were measured for $3 \mathrm{~min}$ after the exercise while the participant was still sitting on the bicycle.

Table 1 Demographics and lifestyle information of participants

\begin{tabular}{|c|c|c|c|}
\hline & Male & Female & Total \\
\hline Participants & $58(47.2 \%)$ & $66(52.8 \%))$ & 124 \\
\hline Age (years) & $20.7 \pm 3.1$ & $20.5 \pm 4.1$ & $20.6 \pm 3.7$ \\
\hline \multicolumn{4}{|l|}{ Ethnic origin } \\
\hline Caucasian (EU) & $36(62.1 \%)$ & $34(51.5 \%)$ & $70(56.5 \%)$ \\
\hline Asian & $5(8.6 \%)$ & $11(16.7 \%)$ & $16(12.9 \%)$ \\
\hline African & $6(10.3 \%)$ & $6(9.1 \%)$ & $12(9.7 \%)$ \\
\hline Others & $11(19.0 \%)$ & $15(22.7 \%)$ & $26(21.0 \%)$ \\
\hline \multicolumn{4}{|l|}{ Residence } \\
\hline UK & $34(58.6 \%)$ & $37(56.1 \%)$ & $71(57.3 \%)$ \\
\hline EU & $9(15.5 \%)$ & $13(19.7 \%)$ & $22(17.7 \%)$ \\
\hline Overseas & $15(25.9 \%)$ & $16(24.2 \%)$ & $31(25.0 \%)$ \\
\hline Hight (cm, measured) & $178.3 \pm 6.3$ & $165.6 \pm 5.8$ & $171 \pm 8.8$ \\
\hline Weight (kg, measured) & $73.2 \pm 9.8$ & $59.7 \pm 8.7$ & $66.0 \pm 11.4$ \\
\hline Average BMI $\left(\mathrm{kg} / \mathrm{m}^{2}\right)$ & $23 \pm 2.6$ & $21.7 \pm 3.2$ & $22.4 \pm 3.0$ \\
\hline Overweight (> $25 \mathrm{~kg} / \mathrm{m}^{2}$ ) & $8(13.8 \%)$ & $6(9.1 \%)$ & $14(11.3 \%)$ \\
\hline Underweight $\left(<18.5 \mathrm{~kg} / \mathrm{m}^{2}\right)$ & $5(8.6 \%)$ & $6(9.1 \%)$ & $11(8.9 \%)$ \\
\hline Normal weight $\left(18.5-24.9 \mathrm{~kg} / \mathrm{m}^{2}\right)$ & $45(77.6 \%)$ & $54(81.8 \%)$ & 99 (80.5\%) \\
\hline Current Smoker & $5(8.6 \%)$ & $6(9.1 \%)$ & $11(8.9 \%)$ \\
\hline \multicolumn{4}{|l|}{ Alcohol use } \\
\hline$\geq 12$ units/week & $26(44.8 \%)$ & $15(22.7 \%)$ & $41(33.1 \%)$ \\
\hline$<4$ unit/week or no alcohol & $32(55.2 \%)$ & $51(77.3 \%)$ & $83(57.9 \%)$ \\
\hline \multicolumn{4}{|l|}{ Moderate Exercise (h/week) } \\
\hline$\geq 3 \mathrm{~h} /$ week & $40(69.0 \%)$ & $41(62.1 \%)$ & $81(65.3 \%)$ \\
\hline$<2.5 \mathrm{~h} /$ week & $18(31.0 \%)$ & $25(37.9 \%)$ & $43(34.7 \%)$ \\
\hline \multicolumn{4}{|l|}{ Outdoor activity at weekend } \\
\hline$>4 \mathrm{~h} /$ per week & $28(48.3 \%)$ & $38(57.6 \%)$ & $66(53.2 \%)$ \\
\hline 0-4 h/per week & $30(51.7 \%)$ & $28(42.4 \%)$ & $58(46.8 \%)$ \\
\hline \multicolumn{4}{|l|}{ Screen-time at weekend } \\
\hline$>3$ h/day & $44(75.9 \%)$ & 59 (89.4\%) & $103(83.1 \%)$ \\
\hline 0-3 h/day & $14(24.1 \%)$ & $7(10.6 \%)$ & $21(16.9 \%)$ \\
\hline \multicolumn{4}{|l|}{ Daily sleep } \\
\hline$<7$ h/day & $35(60.3 \%)$ & $38(57.6 \%)$ & $73(58.9 \%)$ \\
\hline$>7$ h/day & $23(39.7 \%)$ & $28(42.4 \%)$ & $51(41.1 \%)$ \\
\hline \multicolumn{4}{|l|}{ Self-assessment of fitness } \\
\hline Not fit & $17(29.3 \%)$ & $26(39.4 \%)$ & $43(34.7 \%)$ \\
\hline fit & $41(70.7 \%)$ & $40(60.6 \%)$ & 81 (65.3\%) \\
\hline
\end{tabular}




\section{Statistical analysis}

Descriptive statistics included mean with standard deviation for continuous variables and frequency with percentage for categorical variables. If asymmetric then median with interquartile range were reported. A liner regression and hierarchical multiple regression analysis model was used to generate various regression equations for predicting the relative contribution of gender, BMI, PA levels and self-assessment of fitness with $\mathrm{VO}_{2} \max$ values or $\mathrm{HRR}$ at $3 \mathrm{~min}$ as the dependent variables. Pearson correlation and values at 95\% confidence intervals (CI) were used to measures the statistical relationship (or association) between two variables of $\mathrm{VO}_{2}$ max and HRR. Levene's Test was used to determine the equality or homogeneity of variance of the groups. Statistical significance was set at alpha $P<0.05$. Data analyses was performed using the Statistical Package for the Social Sciences (SPSS) version 25 software for windows.

\section{Results}

\section{Demographics and lifestyle components linked to} cardiovascular health

The information of demographics and lifestyle components were given in Table 1 . There were 58 (47.2\%) male and $66(52.8 \%)$ females with an average age of $20.6 \pm 3.7$ years. There were $56.5 \%$ EU Caucasians, $12.9 \%$ Asian and 9.7\% Africans and the rests were other ethnical origins. The majority $(80.5 \%)$ of the students had BMI within the normal range (18.5$\left.24.9 \mathrm{~kg} / \mathrm{m}^{2}\right), 11.3 \%$ were overweight $\left(\mathrm{BMI}>25 \mathrm{~kg} / \mathrm{m}^{2}\right)$ and $8.9 \%$ were underweight $\left(\mathrm{BMI}<18 \mathrm{~kg} / \mathrm{m}^{2}\right)$. Among the participants, $8.9 \%$ described themselves as current smokers. Approximately $33.1 \%$ of the participants admitted to consume alcohol $\geq 12$ units/week (112 g/ week), which is close to the UK safe limit of alcohol consumption ( $\leq 14$ units/week or $112 \mathrm{~g} /$ week) [23] with males occupying the greatest proportion of this category.

Self-reported physical activity (any form of exercise or sport) (h/week) were evaluated according to UK National Physical Activity Guidelines for adults [9]. Of the 124 participants (Table 1), 65.3\% had about $\geq 3 \mathrm{~h} /$ week of moderate exercise, $34.7 \% \mathrm{had}<3 \mathrm{~h} /$ week exercise and $5.6 \%$ did not engage in any form of exercise or sport at all. When asked for reasons for not meeting National Physical Activity Guidelines, the majority responded "no time". When asked about outdoor activity at weekend, $53.2 \%$ students claimed to have in average of $\geq 4 \mathrm{~h}$ outdoors/per weekend and the rest did not. In contrast, $83.1 \%$ of students admitted to spend $>3 \mathrm{~h}$ of screen time/per weekend-day to play games, watch film or TV. Regarding the sleeping time, $58.9 \%$ of students admitted to sleep $<7 \mathrm{~h} /$
A) Impact of physical activities

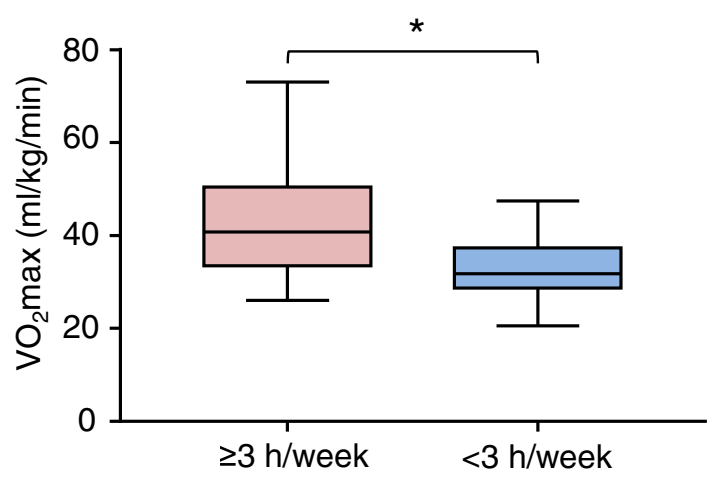

B) Impact of self-assessment of fitness

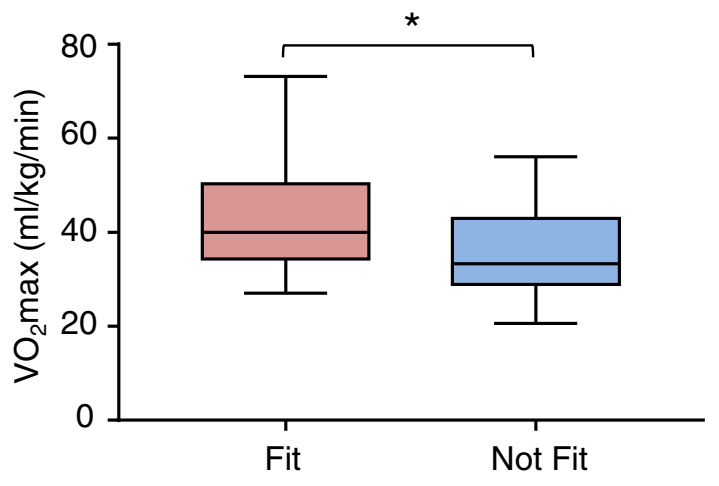

C) Impact of BMI categories

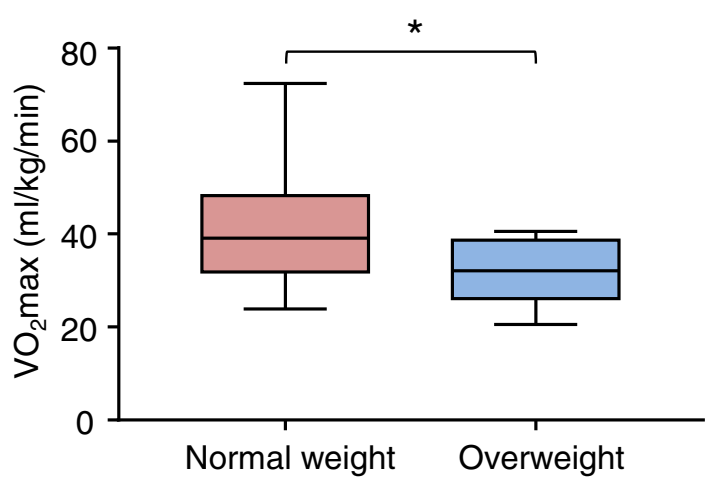

Fig. 1 The impacts of the levels of physical activity, self-assessed fitness and $\mathrm{BMI}$ on $\mathrm{VO}_{2}$ max distribution. a Differences in $\mathrm{VO}_{2}$ max distribution between participants who had $\geq 3 \mathrm{~h}$ /week physical activity versus those who did not, ${ }^{*} P<0.0001$. b. Difference in $\mathrm{VO}_{2}$ max distribution between participants who self-precepted themselves to be physically fit versus those who felt not fit, ${ }^{*} P=0.001$. c Differences in $V_{2}$ max distribution between normal weight versus overweight participants. ${ }^{*} P=0.012$

day which is below the recommendation by UK $\mathrm{Na}$ tional Health Serves [24]. For the self-assessment of physical fitness, $34.7 \%$ of participants perceived themselves as being physically unfit (feeling tired) with females being the majority in this category. 


\section{$\mathrm{VO}_{2}$ max distribution, $\mathrm{HRR}$ and their associations with lifestyle components}

Significant correlations were found between the $\mathrm{VO}_{2} \max$ distribution and the levels of physical activity, selfassessed fitness and BMI (Fig. 1). Those who participated $\geq 3 \mathrm{~h} /$ week of exercise had significant higher values of $\mathrm{VO}_{2}$ max distribution than others $(\mathrm{F}=14.161 ; P<$ 0.001 ). The participants who believed themselves physically fit had significantly higher values of $\mathrm{VO}_{2} \max$ distribution than those who felt not fit $(\mathrm{F}=11.43 ; P=0.001)$. Overweight and obese group had lower values of $\mathrm{VO}_{2}$ max distribution in comparison to the values of normal weight group $(\mathrm{F}=4.555 ; P=0.01)$.

The HRR was measured for $3 \mathrm{~min}$ after the cessation of physical exercise (at time 0) (Fig. 2). The HR decreased quickly in the first $\min$ ( $>25$ beats/min), and then slowed down (Fig. 2a). At 3 min post exercise, the mean HR $(105 \pm 20)$ was still above the resting HR $(80.8 \pm 16.6)$ measured before exercise. We found that $\mathrm{HR}$ at $3 \mathrm{~min}$ post-exercise had a good correlation with
$\mathrm{VO}_{2}$ max distribution (Pearson correlation coefficient $=$ 0.673; 95\% CI: 0.646-1.175; $p<0.0001$ ) (Fig. 2b). Participants who had $<3 \mathrm{~h} /$ week exercise had significantly slower HRR recovery at 3 min than others $(F=8.297$; $P=0.005)$. Participants who believed themselves physically not fit had an attenuated HRR at $3 \mathrm{~min}$ in comparison to those who felt physically fit $(\mathrm{F}=6.767 ; P=0.01)$. Although approximately $33.1 \%$ of the new medical science students admitted to consume alcohol beyond the safe limit, we did not find significant association between the amount of alcohol consumption and $\mathrm{VO}_{2} \max$ (or HRR) in this study. We did not find association between daily sleep time with CRF and HRR.

We also found gender-influence on SBP that females had slightly but significantly lower SBP than males at both rest and after exercise $(\mathrm{F}=42.121 ; P<0.0001)$ (Fig. 3a). There was no significant difference for diastolic BP. BMI also had an impact on resting SBP. The overweight and obese group had higher resting SBP than the normal weight group $(\mathrm{F}=4.934 ; P=0.009)$ and this
A) HRR post-exercise

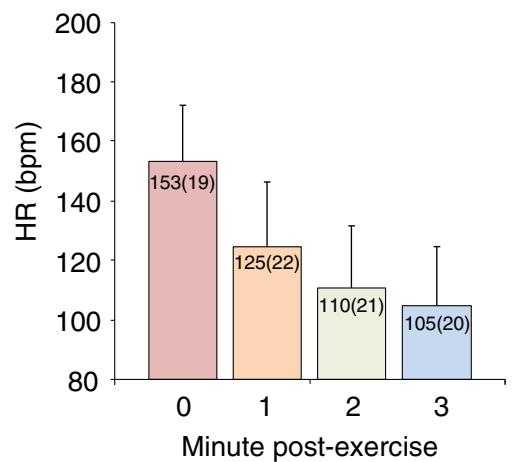

C) Impact of physical activity

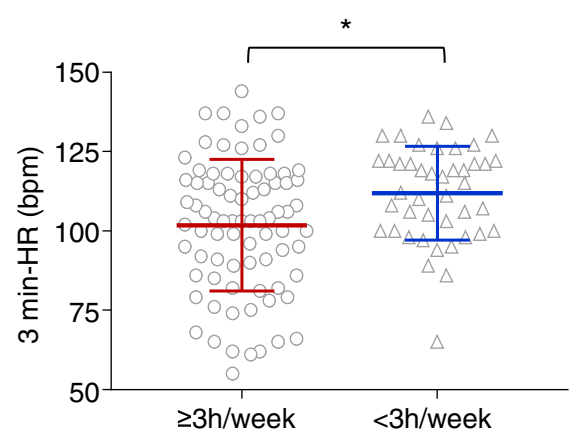

B) Correlation between $\mathrm{VO}_{2} \max$ and 3-min HRR

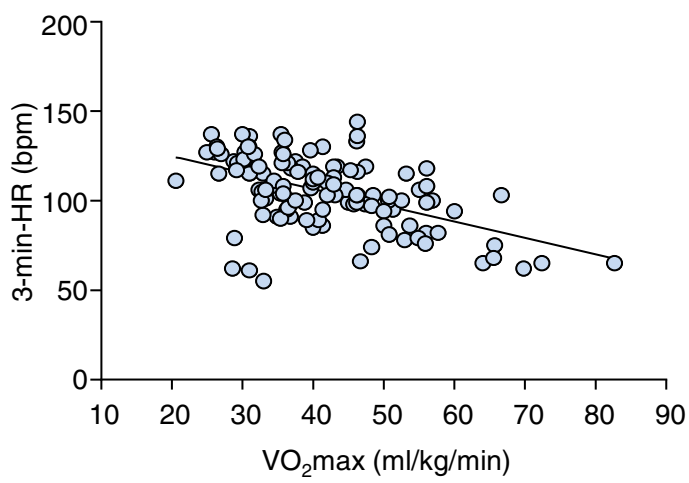

D) Impact of self-assessed fitness

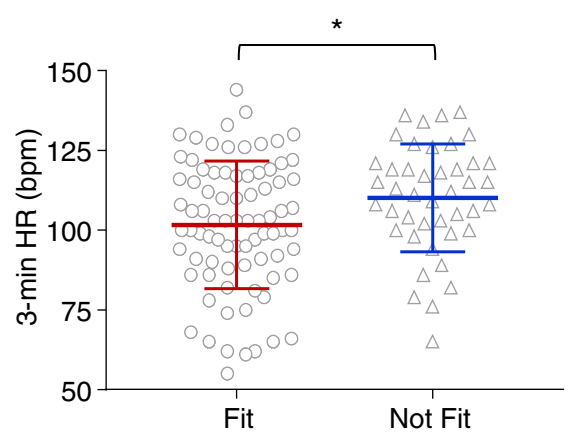

Fig. 2 Heart rate recovery post exercise and significances. a HR measured every min for 3 min post-exercise. Values in the bar represent mean HR and (SD). bpm: beat per minute. $\mathbf{b}$ The correlation between 3-min HRR and VO2max. $r=0.673, P<0.0001$. $\mathbf{c}$ Impact of the levels of exercise on the values of 3 -min $H R R,{ }^{*} P=0.005$. $\mathbf{d}$ Impact of self-assessed fitness on the values of 3 -min HRR. ${ }^{*} P=0.01$ 
A) Difference between genders

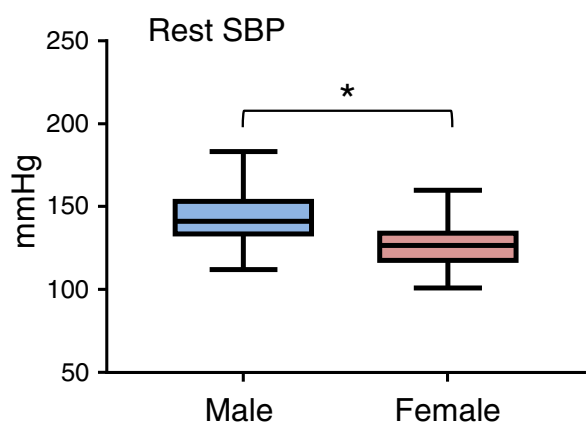

B) Difference between BMI categories

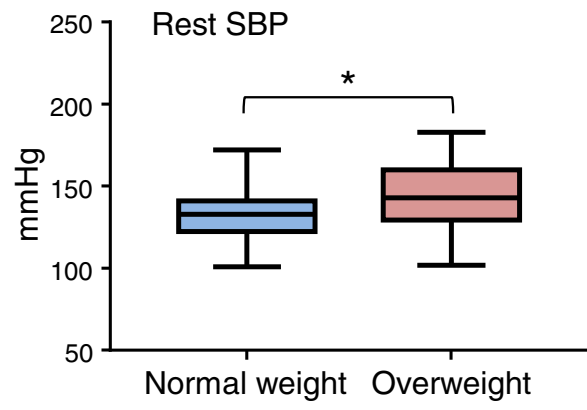

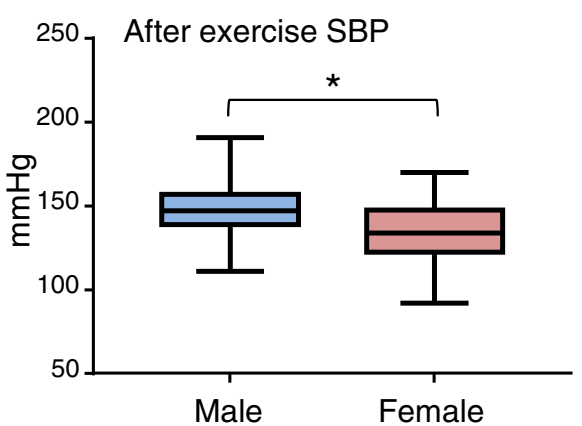

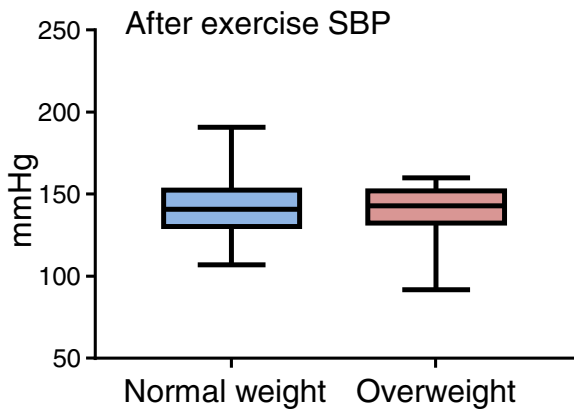

Fig. 3 Impacts of gender and BMI on systolic blood pressure (SBP) at rest (left panels) and after exercise (right panels). a Differences in SBP between males and females. ${ }^{*} P<0.0001$. $\mathbf{b}$ Differences in SBP between normal weight and overweight. ${ }^{*} P<0.01$

difference disappeared after exercise (Fig. 3b), suggesting exercise is beneficial for the young overweigh adults to prevent pre-hypertension syndrome.

\section{Discussion}

Medical science students at university are valuable workplace resources for the development of new medicine and medical technology for a better healthcare. However, studying biomedical science does not mean the students will adapt a healthy lifestyle [4]. In the present study, we examined the lifestyle components through self-filled questionnaires and measured the CRF $\left(\mathrm{VO}_{2} \mathrm{max}\right)$ and HRR distributions of 124 new medical science students. We discovered that a significant proportion (34\%) of these new students failed to meet the UK National Physical Activity Guidelines with CRF distribution and their 3 min-HRR values significantly below the values of their peers. Unhealth lifestyle behaviours together with lack of physical activity had put these young medical science students under greater risk of developing cardiometabolic diseases.

It is well established that low CRF in the young is a prominent risk factor for the development of cardiovascular disease, and regular exercise improves CRF and reduces mental stress [13, 25]. In accordance with previous studies, we found in the present study that $\mathrm{VO}_{2} \mathrm{max}$ distribution was positively associated with the levels of physical activity, self-perception of fitness and BMI. Overall, one in three biomedical students failed in keeping a healthy lifestyle profile of exercise according to UK National Physical Activity Guidelines and felt tired easily. Despite their education in medical science, these young adults had lower CRF and HRR values and increased risks for cardiovascular diseases at later ages.

Attenuated HRR is associated with increased risk of cardiovascular events and all-cause mortality [19]. However, previous studies referred HRR within $1 \mathrm{~min}$ or 2 min after exercises and were for hospital patients [19, 26]. A significant finding in the current study is a close relationship between the 3-min HRR with $\mathrm{VO}_{2}$ max distribution and the levels of exercise and self-assessment of fitness. Further studies are needed to establish the clinical significance of $3 \mathrm{~min}$ HRR in predicting risk of cardiometabolic diseases in the general population.

It had been reported that bouts of exercise at least once during the weekend reduced the risk of metabolic and cardiovascular diseases [27]. Notably, the population in this study was age-matched young health professionals who spent their most weekday time sedentary for academic studies. However, when questioned about leisure-time outdoor activity during the weekends, nearly 
half of participants admitted to spend $<4 \mathrm{~h}$ outdoors of any kind of physical activities per weekend and the majority $(83.1 \%)$ of students admitted to spending $>3 \mathrm{~h} /$ per weekend-day for sedentary screen time. BMI is inversely correlated with CRF which is in accordance with previous studies [27].

There are limitations because the study was conducted in one institution. However, the participants in our study were recruited continually over 4-year period containing a variety of ethnic origins with their home residence crossing several counties, and data were representative for this population. Another limitation is the lifestyle components and levels of habitual physical activity ( $h$ / week) were self-assessed. However, the $\mathrm{VO}_{2} \max$ and HRR of each participant were measured and their correlations to gender, BMI, PA levels and self-assessment of fitness were confirmed statistically.

\section{Conclusion}

This study provides evidence that unhealthy lifestyle has a significant negative impact on the CRF and HRR of young medical science students. One in three participants failed to meet UK National Physical Activity Guidelines and self-perceived to be physically not fit along with their CRF and HRR values being significantly lower than the values expected for their age, which put them at increased risk of cardiometabolic diseases at later age. We found that $3 \mathrm{~h} /$ week exercise (any form and strength) at university is necessary for maintaining healthy CRF and HRR. We also found a good correlation between 3 min-HRR post-submaximal exercise with $\mathrm{VO}_{2} \mathrm{max}$ and the levels of physical activity, and $3 \mathrm{~min}$ HRR can be a valuable indicator for cardiorespiratory function. Encouraging regular exercise and to implement healthy lifestyle changes should be a priority for the long-term health of young adults in medical science education.

\section{Supplementary information}

Supplementary information accompanies this paper at https://doi.org/10. 1186/s12889-020-09154-x.

Additional file 1. Activity \& lifestyle questionnaire.

\section{Abbreviations}

CRF: Cardiorespiratory fitness; HRR: Heart rate recovery; BMI: Body mass index

\section{Acknowledgements}

Not applicable.

\section{Authors' contributions}

LMF: data analysis and manuscript drafting. AC and JML: ethical approval application and data collection, GL: statistics; JML critically reviewed manuscript. The authors read and approved the final manuscript.

\section{Funding}

This research was supported by the British Heart Foundation (PG/06/073/ 21118; and PG/14/85/31161) for study design, data analysis and interpretation and manuscript preparation.

Availability of data and materials

The datasets generated during and/or analysed during the current study are available from the corresponding author on reasonable request.

\section{Ethics approval and consent to participate}

This study was approved by the research ethics committee of the Faculty of Health and Medical Science at the University of Surrey (EC/2011/38), UK. Written consents were received from participants together with survey questionnaires.

\section{Consent for publication}

Not applicable.

\section{Competing interests}

The authors declare that they have no competing interests.

\section{Author details}

${ }^{1}$ Department of Cardiology, The Royal Wolverhampton NHS Trust, Wolverhampton, UK. ${ }^{2}$ Faculty of Health and Medical Sciences, University of Surrey, Guildford, UK. ${ }^{3}$ School of Biological Sciences, Harborne Building, University of Reading, Whiteknights, Reading RG6 6AS, UK.

Received: 7 January 2020 Accepted: 19 June 2020

Published online: 26 June 2020

\section{References}

1. Higher Education Student Statistics: UK, 2017/18 - Subjects studied [https:// www.hesa.ac.uk/news/17-01-2019/sb252-higher-education-student-statistics/ subjects]. Accessed 13 Sept 2019.

2. Riegel B, Moser DK, Buck HG, Dickson W, Dunbar SB, Lee CS, Lennie TA, Lindenfeld J, Mitchell JE, Treat-Jacobson DJ, et al. Self-Care for the Prevention and Management of cardiovascular disease and stroke: a scientific statement for healthcare professionals from the American Heart Association. J Am Heart Assoc. 2017;6:e006997. https://doi.org/10.1161/ JAHA.117.006997.

3. Lee IM, Shiroma EJ, Lobelo F, Puska P, Blair SN, Katzmarzyk PT. Lancet physical activity series working G: effect of physical inactivity on major noncommunicable diseases worldwide: an analysis of burden of disease and life expectancy. Lancet. 2012;380(9838):219-29.

4. Bhatti SN, Leidi A, Leake D, Li JM. Studying biological science does not lead to adoption of a healthy lifestyle. Perspect Public Health. 2019. https://doi. org/10.1177/1757913919890889.

5. Penkala S, El-Debal H, Coxon K. Work-related musculoskeletal problems related to laboratory training in university medical science students: a cross sectional survey. BMC Public Health. 2018;18(1):1208.

6. Lloyd-Jones DM, Hong Y, Labarthe D, Mozaffarian D, Appel L, Van Horn L, Greenlund K, Daniels S, Nichol G, Tomaselli GF, et al. Defining and setting national goals for cardiovascular health promotion and disease reduction: the American Heart Association's strategic impact goal through 2020 and beyond. Circulation. 2010;121(4):586-613.

7. Mok A, Khaw KT, Luben R, Wareham N, Brage S. Physical activity trajectories and mortality: population based cohort study. BMJ. 2019;365:12323.

8. Heron L, O'Neill C, McAneney H, Kee F, Tully MA. Direct healthcare costs of sedentary behaviour in the UK. J Epidemiol Community Health. 2019;73(7): 625-9.

9. Physical activity guildelines for adults (19-64 years) [https://www.gov.uk/ government/publications/uk-physical-activity-guidelines ]. Accessed $13 \mathrm{Sept}$ 2019.

10. Knaeps S, Bourgois JG, Charlier R, Mertens E, Lefevre J, Wijndaele K. Ten-year change in sedentary behaviour, moderate-to-vigorous physical activity, cardiorespiratory fitness and cardiometabolic risk: independent associations and mediation analysis. Br J Sports Med. 2018;52(16):1063-8.

11. Davidson T, Vainshelboim B, Kokkinos P, Myers J, Ross R. Cardiorespiratory fitness versus physical activity as predictors of all-cause mortality in men. Am Heart J. 2018;196:156-62. 
12. Kokkinos P, Kaminsky LA, Arena R, Zhang J, Myers J. A new generalized cycle ergometry equation for predicting maximal oxygen uptake: the fitness registry and the importance of exercise National Database (FRIEND). Eur J Prev Cardiol. 2018;25(10):1077-82.

13. Blair SN, Kampert JB, Kohl HW 3rd, Barlow CE, Macera CA, Paffenbarger RS $\mathrm{Jr}$, Gibbons LW. Influences of cardiorespiratory fitness and other precursors on cardiovascular disease and all-cause mortality in men and women. JAMA. 1996;276(3):205-10.

14. Kim CH, Wheatley $\mathrm{CM}$, Behnia M, Johnson BD. The effect of aging on relationships between lean body mass and VO2max in rowers. PLoS One. 2016;11(8):e0160275

15. Sharma HB, Kailashiya J. Gender difference in aerobic capacity and the contribution by body composition and Haemoglobin concentration: a study in young Indian National Hockey Players. J Clin Diagn Res. 2016;10(11): CCO9-13.

16. Kokkinos P, Myers J, Franklin B, Narayan P, Lavie CJ, Faselis C. Cardiorespiratory fitness and health outcomes: a call to standardize fitness categories. Mayo Clin Proc. 2018;93(3):333-6.

17. Lakka TA, Laaksonen DE, Lakka HM, Mannikko N, Niskanen LK, Rauramaa R, Salonen JT. Sedentary lifestyle, poor cardiorespiratory fitness, and the metabolic syndrome. Med Sci Sports Exerc. 2003;35(8):1279-86.

18. Knaeps S, Lefevre J, Wijtzes A, Charlier R, Mertens E, Bourgois JG Independent associations between sedentary time, moderate-to-vigorous physical activity, cardiorespiratory fitness and cardio-metabolic health: a cross-sectional study. PLoS One. 2016;11(7):e0160166.

19. Qiu S, Cai X, Sun Z, Li L, Zuegel M, Steinacker JM, Schumann U. Heart Rate Recovery and Risk of Cardiovascular Events and All-Cause Mortality: A MetaAnalysis of Prospective Cohort Studies. J Am Heart Assoc. 2017;6(5). https:// doi.org/10.1161/JAHA.117.005505.

20. Adult tobacco use information, General concepts [https://www.cdc.gov/ nchs/nhis/tobacco/tobacco_glossary.htm]. Accessed 21 Aug 2019.

21. Noonan V, Dean E. Submaximal exercise testing: clinical application and interpretation. Phys Ther. 2000;80(8):782-807.

22. Astrand PO, Ryhming I. A nomogram for calculation of aerobic capacity (physical fitness) from pulse rate during sub-maximal work. J Appl Physiol. 1954; $7(2): 218-21$

23. Alcohol consumption: advice on low risk drinking [https://www.gov.uk/ government/publications/alcohol-consumption-advice-on-low-risk-drinking]. Accessed 02 May 2019

24. How to get to sleep, Sleep and tiredness [https://www.nhs.uk/live-well/ sleep-and-tiredness/how-to-get-to-sleep/]. Accessed 13 Sept 2019.

25. Rahman MS, Helgadottir B, Hallgren M, Forsell Y, Stubbs B, Vancampfort D, Ekblom O. Cardiorespiratory fitness and response to exercise treatment in depression. BJPsych Open. 2018;4(5):346-51.

26. Dhoble A, Lahr BD, Allison TG, Kopecky SL. Cardiopulmonary fitness and heart rate recovery as predictors of mortality in a referral population. J Am Heart Assoc. 2014;3(2):e000559. https://doi.org/10.1161/JAHA.113.000559.

27. Sieverdes JC, Sui X, Lee DC, Church TS, McClain A, Hand GA, Blair SN. Physical activity, cardiorespiratory fitness and the incidence of type 2 diabetes in a prospective study of men. Br J Sports Med. 2010;44(4):238-44.

\section{Publisher's Note}

Springer Nature remains neutral with regard to jurisdictional claims in published maps and institutional affiliations.

Ready to submit your research? Choose BMC and benefit from:
- fast, convenient online submission
- thorough peer review by experienced researchers in your field
- rapid publication on acceptance
- support for research data, including large and complex data types
- gold Open Access which fosters wider collaboration and increased citations
- maximum visibility for your research: over 100M website views per year
At BMC, research is always in progress.
Learn more biomedcentral.com/submissions

